\title{
Anosmin-1 Modulates Fibroblast Growth Factor Receptor 1 Signaling in Human Gonadotropin-Releasing Hormone Olfactory Neuroblasts through a Heparan Sulfate-Dependent Mechanism
}

\author{
David González-Martínez, ${ }^{1}$ Soo-Hyun Kim, ${ }^{1}$ Youli Hu, ${ }^{1}$ Scott Guimond, ${ }^{2}$ Jonathan Schofield, ${ }^{1}$ Paul Winyard, ${ }^{3}$ \\ Gabriella Barbara Vannelli, ${ }^{4}$ Jeremy Turnbull, ${ }^{2}$ and Pierre-Marc Bouloux ${ }^{1}$ \\ ${ }^{1}$ Centre for Neuroendocrinology, Royal Free and University College Medical School, London NW3 2PF, United Kingdom, ${ }^{2}$ School of Biological Sciences, \\ University of Liverpool, Liverpool L69 7ZB, United Kingdom, ${ }^{3}$ Nephro-Urology Unit, Institute of Child Health, London WC1N 1EH, United Kingdom, and \\ ${ }^{4}$ Department of Human Anatomy, University of Florence, School of Medicine, I-50134 Florence, Italy
}

\begin{abstract}
Defects of either anosmin-1 or fibroblast growth factor receptor 1 (FGFR1) are known to underlie hereditary Kallmann's syndrome (KS), a human disorder of olfactory and gonadotropin-releasing hormone $(\mathrm{GnRH})$ neuronal ontogeny. Here, we report a functional interaction between anosmin-1 and the FGFR1-FGF2- heparan sulfate complex, leading to amplified responses in the FGFR1 signaling pathway. In human embryonic GnRH olfactory neuroblasts, wild-type anosmin-1, but not proteins with loss-of-function KS mutations, induces neurite outgrowth and cytoskeletal rearrangements through FGFR1-dependent mechanisms involving p $42 / 44$ and p38 mitogen-activated protein kinases and Cdc42/Rac1 activation. Furthermore, anosmin-1 enhances FGF2 signaling specifically through FGFR1 IIIc in heterologous BaF3 lymphoid cells in a heparan sulfate-dependent manner. Our study provides compelling evidence for anosmin-1 as an isoform-specific co-ligand modulator of FGFR signaling that amplifies and specifies FGFR1 signaling responses during human nervous system development and defines a mechanism underlying the link between autosomal and X-linked KS.
\end{abstract}

Key words: FGFR1; GnRH; anosmin-1; heparan sulfate proteoglycans; Kallmann's syndrome; MAPKs

\section{Introduction}

Both olfactory and gonadotropin-releasing hormone (GnRH)secreting neurons originate in the nasal compartment (Tobet et al., 2001); during development, olfactory axons establish contact with the olfactory bulb (OB) anlage, a prerequisite for proper $\mathrm{OB}$ formation (Graziadei and Monti Graziadei, 1986), whereas GnRH cells follow an axonophilic migratory route toward the hypothalamic area (Wray et al., 1989). In X-linked Kallmann's syndrome (X-KS), anosmia and reproductive dysfunction occur secondary to $\mathrm{OB}$ dysgenesis and hypothalamic GnRH deficiency, respectively (MacColl et al., 2002); initial differentiation and migration of nasal compartment neurons appear normal, the developmental defects lying in the subsequent axonal elongation, pathfinding, and/or terminal differentiation process. Mutations of KAL-1 gene underlie X-KS (Franco et al., 1991; Legouis et al., 1991). KAL-1 is expressed in the OB, cerebellum, spinal cord, kidney, and retina during development; its encoded protein, anosmin-1, is a secreted, extracellular matrix (ECM)-associated

Received July 1, 2004; revised Oct. 1, 2004; accepted 0ct. 5, 2004.

We thank the Human Developmental Biology Resource in London and Newcastle funded by the Medical Research Council and the Wellcome Trust for supplying the human embryo tissues and Dr. Andrew Powell (University of Liverpool, Liverpool, UK) for provision of recombinant FGFR1 IIIc protein.

Correspondence should be addressed to Dr. Pierre-Marc Bouloux, Centre for Neuroendocrinology, Royal Free and University College Medical School, Rowland Hill Street, London NW3 2PF, UK. E-mail: pbouloux@rfc.ucl.ac.uk. DOI:10.1523/JNEUROSCI.3400-04.2004

Copyright $\odot 2004$ Society for Neuroscience $\quad$ 0270-6474/04/2410384-09\$15.00/0 glycoprotein, comprising an N-terminal cysteine-rich region, a whey acidic protein-like four disulfide core motif (WAP), and four tandem fibronectin type III (FnIII)-like repeats, followed by a histidine-rich $\mathrm{C}$ terminus. The WAP domain is found in several serine protease inhibitors. The FnIII domains, homologous to the neural cell adhesion molecule (N-CAM) family (Robertson et al., 2001), show a heparan sulfate (HS) binding affinity (Hu et al., 2004). Anosmin-1 functions as a cellular adhesion or local guidance molecule, stimulating axonal branching from rodent OB explants (Soussi-Yanicostas et al., 2002) and promoting cell adhesion and neurite outgrowth in coculture experiments (Soussi-Yanicostas et al., 1998). In Caenorhabditis elegans, KAL-1 overexpression causes axon branching and pathfinding defects (Bulow et al., 2002).

Fibroblast growth factor receptor 1 (FGFR1), a member of the receptor tyrosine kinase family (Simon, 2000), has recently been identified as $K A L-2$, a putative autosomal-KS (A-KS) gene (Dode et al., 2003). Involvement of FGFR signaling in organogenesis is well documented (Coumoul and Deng, 2003). FGFs signal through their respective receptors in a highly localized and regulated manner during neural development (Dono, 2003). Coexpression of FGF2 and FGFR1 is detected in nasal epithelium and the vomeronasal body (Britto et al., 2002). Targeted disruption of Fgfr1 in mouse telencephalon results in OB aplasia (Hebert et al., 2003), whereas mice with a partial $F g f 8$ loss exhibit a small telencephalon without an OB and a normal midline (Meyers et al., 1998).

Both FGFR1 and anosmin-1 require heparan sulfate proteo- 
glycans (HSPGs) for their biological functions. HS is essential for FGF-FGFR complex formation and receptor activation (Guimond and Turnbull, 1999). Anosmin-1 diffuses and binds to adjacent cell surfaces only in the presence of HSPG (SoussiYanicostas et al., 1996). In the KAL-1 transgenic C. elegans model, the anosmin-1-induced axonal branching phenotype is suppressed in heparan-6O-sulfotransferase- and C5-epimerasedeficient backgrounds (Bulow and Hobert, 2004).

Here, we show that anosmin-1-mediated activation of FGFR1 signaling induces neurite outgrowth and cytoskeletal rearrangement in human embryonic GnRH olfactory neuroblasts. The two KS gene products cooperate within a multimeric FGFR1-FGF2HSPG-anosmin-1 complex leading to functional and specific activation of FGFR1 signaling pathways involving p42/44 and p38 mitogen-activated protein kinases (MAPKs) and Cdc42/Rac1, providing direct evidence that anosmin-1 regulates FGFR1 signaling through an HS-dependent interaction.

\section{Materials and Methods}

FNC-B4 cell culture and neurite outgrowth assay. Isolation and propagation of primary human olfactory neuroblast culture FNC-B4 were described previously (Vannelli et al., 1995). For neurite outgrowth assay, $7.5 \times 10^{3}$ cells that had been serum starved for $24 \mathrm{hr}$ were seeded per well in a 96-well plate with $50 \mu \mathrm{l}$ of serum-free medium containing collagen matrix (Chemicon, Temecula, CA) along with various recombinant proteins and specific inhibitors (see below). After a $48 \mathrm{hr}$ incubation in $37^{\circ} \mathrm{C}$, cells were stained with Syto Green (Molecular Probes, Eugene, OR), and pictures of random fields were taken in a double-blind manner. The length of the longest neurite and the cell body diameter were measured using Lucia software (Nikon Instruments, Tokyo, Japan). Generation of wild-type or mutant recombinant anosmin-1 proteins (Hu et al., 2004) and FGFR1 ectodomain fused with IgFc (Anderson et al., 1998) was described previously. Other recombinant proteins and antibodies used were human FGF2 (Abcam, Cambridge, Cambridgeshire, UK), antianosmin-1 antibody (raised against PIWF1 in our laboratory), anti-FGF2, and anti-FGFR1 ectodomain antibody (Santa Cruz Biotechnology, Santa Cruz, CA). To block specific signaling pathways, $20 \mu \mathrm{M}$ SU5402, (3-[3-(2carboxyethyl)-4-methylpyrrol-2-methylidenyl]-2-indolinone), $100 \mu \mathrm{M}$ PD98059 (2'-amino-3'-methoxyflavone), and $25 \mu \mathrm{M}$ SB203580 (4-(4fluorophenyl)-2-(4-methylsulfinylphenyl)-5-(4-pyridyl) $1 \mathrm{H}$-imidazole) (Calbiochem, La Jolla, CA) were used.

Immunochemistry of embryo sections and cells. One 30-d-old [Carnegie stage (CS) 14], two 50-d-old (CS22), and two 56-d-old (CS23) normal human embryos were collected from chemically and surgically induced terminations with the patients' consent and with ethical approval from the Institute of Child Health Ethical Committee, University College London. Immunohistochemistry was performed on sagittal sections of paraffin-embedded heads. The antibodies used were anti-anosmin-1, anti-GnRH (DiaSorin, Stillwater, MA), anti-FGFR1 $\alpha$ (M2F12) endodomain antibody (Abcam), and anti-rabbit or anti-mouse secondary antibody conjugated with either Texas Red or FITC (Jackson ImmunoResearch, West Grove, PA). For double immunohistochemistry using streptavidin-biotin-peroxidase and alkaline phosphatase methods, sections pretreated with $3 \%$ hydrogen peroxide were blocked with $5 \%$ normal goat serum (NGS) in PBS with $0.5 \%$ Triton-X (PBST) and incubated overnight with anti-anosmin-1 antibody. After washing with PBST, they were incubated with biotin-sp-conjugated AffiniPure anti-rabbit goat IgG antibodies, washed, and incubated with peroxidase-conjugated streptavidin complex (Jackson ImmunoResearch). To visualize the peroxidase activity, sections were washed in PBST and $0.05 \mathrm{~m}$ Tris- $\mathrm{HCl}, \mathrm{pH}$ 7.6, before incubation in $0.05 \mathrm{M}$ Tris- $\mathrm{HCl}, \mathrm{pH} 7.6$, containing $0.025 \%$ 3,3'-diaminobenzidine tetrahydrochloride (Sigma, St. Louis, MO). After a wash, incubation with levamisole to inhibit endogenous alkaline phosphatase activity, and blocking in 5\% NGS, sections were incubated again overnight with either anti-GnRH or anti-FGFR1 endodomain antibodies. They were then washed and developed with the appropriate alkaline phosphatase-conjugated secondary antibodies and Fast Red (Dako Cy- tomation, Cambridge, Cambridgeshire, UK) in $1 \mathrm{~mm}$ levamisole solution. To confirm the specificity of the antibodies, corresponding control reactions were also performed by preincubating the primary antisera with its corresponding antigen (in the case of anosmin-1), using preimmune antisera, or omitting primary or biotinylated antisera.

To visualize cell surface-associated recombinant anosmin-1 in FNC-B4 cells in the presence or absence of HS, serum-starved cells were incubated for $24 \mathrm{hr}$ with $1 \mathrm{~nm}$ PIWF1, with or without previous addition of $100 \mu \mathrm{g} / \mathrm{ml}$ HS (Sigma-Aldrich, St. Louis, MO). Immunocytochemistry using anti-anosmin-1 antibody was performed under nonpermeabilizing conditions. For cytoskeletal filamentous-actin (F-actin) and vinculin staining, $2 \times 10^{3}$ cells were seeded in chamber slides with serumfree medium containing either $100 \mathrm{~nm}$ bovine serum albumin (BSA), 1 nм PIWF4, or 1.5 nм FGF2. After $48 \mathrm{hr}$ in $37^{\circ} \mathrm{C}$, cells were stained with TexasRed-conjugated phalloidin and a vinculin monoclonal antibody, followed by anti-mouse FITC-conjugated secondary antibody incubation. Pictures were taken using either Axioplan (Zeiss, Oberkochen, Germany) and TCS SP2 confocal (Leica, Nussloch, Germany) microscopes or an Axioplan 2 bright-field/fluorescence microscope (Zeiss).

Western blot, coimmunoprecipitation, and pull-down assay. For Western blot analysis of MAPKs, FNC-B4 cells were serum starved for $24 \mathrm{hr}$ before being stimulated with $1 \mathrm{~nm}$ PIWF4, $1.5 \mathrm{~nm}$ FGF2, or 10\% fetal bovine serum. Cells were then harvested at various time points, and total cell lysates were prepared in lysis buffer (1\% Triton X-100, $50 \mathrm{~mm}$ Tris $\mathrm{HCl}, \mathrm{pH} 8.0$, and $150 \mathrm{~mm} \mathrm{NaCl}$ ) containing inhibitors of proteases and phosphatases. The phosphorylation status of p42/44, p38, and c-Jun $\mathrm{NH}_{2}$-terminal kinase (JNK) MAPKs were analyzed by using phosphorylation- or nonphosphorylation-specific antibodies (Cell Signaling, Beverly, MA). For immunoprecipitation, total cell lysates from serum-starved FNC-B4 cells were prepared in buffer containing $50 \mathrm{~mm}$ HEPES, pH 7.4, $150 \mathrm{~mm} \mathrm{NaCl}, 1.5 \mathrm{~mm} \mathrm{MgCl}_{2}, 1$ mм EGTA, 10\% glycerol, $1 \%$ Triton $\mathrm{X}-100,50 \mathrm{~mm} \mathrm{NaF}, 1 \mathrm{~mm} \mathrm{Na} \mathrm{VO}_{4}, 1$ mm phenylmethylsulfonyl fluoride, and $1.9 \mu \mathrm{g} / \mathrm{ml}$ aprotinin. The precleared cell lysates ( $1.5 \mathrm{mg}$ ) with or without the addition of $500 \mathrm{ng}$ of PIWF4 were immunoprecipitated with $1.5 \mu \mathrm{g}$ of anti-FGFR1 endodomain antibody overnight at $4^{\circ} \mathrm{C}$. Samples were then washed in buffer containing 20 mM HEPES, pH 7.4, $150 \mathrm{~mm} \mathrm{NaCl}, 0.1 \%$ Triton X-100, and $10 \%$ glycerol and analyzed by Western blotting using anti-His (Invitrogen, Paisley, UK), anti-HS (10E4 epitope; Seikagaku America), anti-FGFR1 ectodomain, and anti-FGF2 antibodies. As positive controls, $50 \mathrm{ng}$ of PIWF4 and $50 \mu \mathrm{g}$ of total cell lysate were loaded per lane. For the pull-down assay, the Rac/Cdc42 activation assay kit (Chemicon) was used according to the manufacturer's protocol. Recombinant glutathione S-transferase (GST)-p21activated kinase 1 (PAK1) was detected using anti-GST antibody (Pharmacia/Pfizer, Peapack, NJ).

Reverse transcription-PCR. Total RNA extracted from FNC-B4 cells using TRIzol (Invitrogen) was reverse transcribed using the First-Strand cDNA Synthesis kit (Amersham Biosciences, Piscataway, NJ). The PCR primer sequences and parameters for different FGFR isoforms, $K A L-1$, GnRH-1, and $\beta$-actin are available as supplemental material at www.jneurosci.org.

BaF3 cell proliferation assay. BaF3 cells expressing the IIIc isoforms of FGFR1, FGFR2, or FGFR3 were kindly provided by David Ornitz (Washington University, St. Louis, MO) and maintained as described previously (Ornitz et al., 1996). For proliferation assays, $10^{4}$ cells per well were plated in a 96-well plate with $100 \mu \mathrm{l}$ of culture medium [RPMI 1640 supplemented with $10 \%$ fetal calf serum, 2 mM L-glutamine, and antibiotics, without interleukin-3 (IL-3)] and incubated with $2 \mathrm{ng} / \mathrm{ml} \mathrm{IL-3} \mathrm{(R} \mathrm{\&}$ D Systems Europe, Abingdon, Oxon, UK) or recombinant human FGF2 (R \& D Systems Europe) and porcine intestinal mucosa heparin (Sigma), along with the indicated concentrations of anosmin-1. After $72 \mathrm{hr}$ at $37^{\circ} \mathrm{C}$, a cell proliferation assay using 3-[4,5-dimethylthiazol-2-yl]-2,5-diphenyltetrazolium bromide (MTT) was performed as described previously (Guimond and Turnbull, 1999).

Statistical analysis. Statistical significance at $p<0.01$ was calculated by Student's $t$ test from three independent experiments (see Fig. $3 B$ ) and one-way ANOVA with the Dunnett test for multiple comparisons from five independent experiments using SPSS (Chicago, IL) 10.0 software (see Fig. 3C). 


\section{Results}

Expression of anosmin-1, FGFR1, and GnRH in the human olfactory compartment

Olfactory and GnRH progenitor cells first appear in the olfactory placode (OP) and subsequently migrate toward the rostral forebrain (Schwanzel-Fukuda and Pfaff, 1989). Our immunofluorescence analysis confirmed the presence of anosmin-1, FGFR1, and $\mathrm{GnRH}$ in human embryonic OP as early as 4.5 weeks (CS14) (Fig. $1 A, B)$. GnRH- and FGFR1-positive cells were distributed along the OP, but only the cells in the medial region coexpressed both proteins, albeit at low levels (Fig. $1 \mathrm{~A}$, arrowheads). Investigation of anosmin-1 and FGFR1 distribution in an adjacent section revealed their presence along the OP (Fig. $1 B$ ). At 7 weeks (CS22), neither GnRH cells nor anosmin-1 could be detected in the olfactory epithelium (OE) (Fig. 1C,D), and only GnRH-expressing cells were found in the terminal nerve (TN) (Fig. 1C); the absence of anosmin-1 at this phase of development has been described previously (Hardelin et al., 1999). At 8 weeks of development (CS23), expression of both anosmin-1 and FGFR1 was found in the TN (Fig. $1 E, F$ ), double immunohistochemical analysis of this region indicating that they were presently close to each other (Fig. $1 E)$. Investigation of anosmin-1 and GnRH expression on an adjacent section of the TN (Fig. 1G,H) again shows the expression of both in this region (Fig. $1 G$ ). These data support a potential in vivo interaction between FGFR1 and anosmin-1 at these sites during olfactory GnRH system development.

\section{Characterization of FNC-B4 cells}

FNC-B4 cells are primary neuroblast cultures derived from the human fetal olfactory neuroepithelium. These cells express several olfactory and neuron-specific markers including neurofilament, N-CAM, NSE (human neuron-specific enolase), OMP (olfactory marker protein), $\mathrm{G}_{\mathrm{olf}} \alpha$ (olfactory-specific GTP-binding protein $\alpha$ subunit), OCNC (olfactory cyclic-nucleotide-gated channel), and Olf-1 (olfactory transcription factor-1) (Vannelli et al., 1995). They also express $\mathrm{GnRH}$ and $\mathrm{GnRH}$ receptor and respond to autocrine GnRH stimulation (Romanelli et al., 2004). They therefore represent premigratory neuronal precursor cells that retain properties of both olfactory and GnRH neurons. We investigated FGFR expression in these cells by using isoformspecific PCR primers and demonstrated that both the $b$ and $c$ isoforms of FGFR1 and FGFR3, but only the $b$ isoform of FGFR2, were present (Fig. 1A). Expression of their cognate ligands, FGF1 and FGF2, was also confirmed by Western blotting, implying that FGFR pathways are functionally used in these cells (Fig. 1B). However, anosmin-1 could not be detected by reverse transcription (RT)-PCR (Fig. 1C) or immunocytochemistry (data not shown). FNC-B4 cells thus provide a model system to investigate whether anosmin-1 has an effect(s) on FGFR1-mediated signaling events that may occur during olfactory GnRH system development.

\section{Anosmin-1 induces neurite outgrowth in FNC-B4 cells}

We recently generated a Drosophila S2 cell line enabling a relatively large-scale production of purified recombinant anosmin-1 protein (Fig. 2). PIWF4 represents the full-length wild-type anosmin-1 with four FnIII domains, whereas the truncated version, PIWF1, contains just one. Two other mutant derivatives, designated as mPIWF4 and mPIWF1, incorporated a C172R mutation identified in three X-KS-affected brothers, which disrupts one of the four disulfide core motifs in the WAP domain (Robertson et al., 2001).

To test the effect of anosmin-1 on neuronal differentiation of
FNC-B4 cells, we established a three-dimensional collagen matrix culture system and examined the phenotypic changes induced by anosmin-1. Cells without any treatment or treated with $100 \mathrm{~nm}$ BSA exhibited a mainly round or fusiform shape with short neurites and undefined patterns of branching. In contrast, cells treated with 1-10 nM anosmin-1 showed more spindleshaped bipolar and occasionally multipolar morphology with longer neurite extensions and axonal branching (Fig. 3A). Treatment with $1.5 \mathrm{~nm}$ recombinant human FGF2 also induced a comparable neurite outgrowth phenotype. We then determined the dose dependency of the anosmin-1 effect and whether the X-KS mutants still retain this ability. Cells were incubated with varying concentrations of PIWF4, mPIWF4, PIWF1, or mPIWF1, and the mean length of the longest neurite was statistically compared with that of BSA treatment. PIWF4 caused a significant increase of neurite length in a dose-dependent biphasic manner that peaked at a $1 \mathrm{nM}$ concentration $(p<0.05)$. PIWF1 showed similar effects, whereas the two WAP domain mutants, mPIWF4 and mPIWF1, did not (Fig. 3B). To further analyze this phenomenon, we measured the ratio between the longest neurite length and cell body diameter and calculated the percentage of cells with a particular ratio. In BSA-treated culture, only $\sim 20 \%$ of cells had neurites longer than four times its cell body, but after treatment with $1.5 \mathrm{~nm}$ FGF2 or $1 \mathrm{~nm}$ PIWF4, it increased to $\sim 40 \%(p<0.01)$. Thus, anosmin-1 could induce responses equivalent to those achieved by the addition of relatively high concentrations of exogenous FGF2. Again, PIWF1 behaved similarly to PIWF4, whereas mPIWF1 or PIWF1 preincubated with its neutralizing antibody showed the same level as that of BSA treatment. There was no additional increase when FGF2 and PIWF1 were added together, possibly indicating the saturation of the available receptors (Fig. 3C,D). Thus, anosmin-1 induces neurite outgrowth in a dose-dependent manner; although an intact WAP domain is necessary for this effect, only one FnIII domain is sufficient. Because PIWF1 is indistinguishable from the wild-type PIWF4 in these assays, we pursued our studies using PIWF1, which generated a better yield of recombinant protein production.

We next asked whether the FGFR1 signaling pathway is involved in the anosmin-1-induced phenotype and repeated the assay in the presence of FGFR1-specific inhibitors. Preincubation of cells with an anti-FGF2 antibody or the FGFR1 antagonist SU5402 (Mohammadi et al., 1997) blocked FGF2-induced neurite outgrowth. Importantly, the effect of PIWF1 was also inhibited by SU5402 and anti-FGFR1 antibody. Moreover, the addition of FR1FC, a soluble recombinant FGFR1 ectodomain (Anderson et al., 1998), competed off the PIWF1 effect. Taken together, these data indicate that the anosmin-1 effect is dependent on FGFR1, especially the availability of its ectodomain, suggesting a role for anosmin-1 in modulating the extracellular ligand-receptor interaction (Fig. $3 C, D$ ). It is not possible to conclude, however, whether anosmin-1 directly interacts with the FGFR1 or indirectly cooperates with other ligands to enhance the signaling, because FNC-B4 cells constitutively express endogenous FGF1 and FGF2, which may work by autocrine and paracrine mechanisms (Fig. 1B) (Ensoli et al., 1998).

\section{Anosmin-1 physically interacts with FGFR1-FGF2-HSPG complex}

To understand the nature of anosmin-1-FGFR1 interaction, we performed a coimmunoprecipitation assay using an FGFR1 endodomain antibody. Western blot analysis of the immune complex shows FGFR1 coprecipitates with endogenous FGF2. From the several endogenous HSPG species present in the total 
A

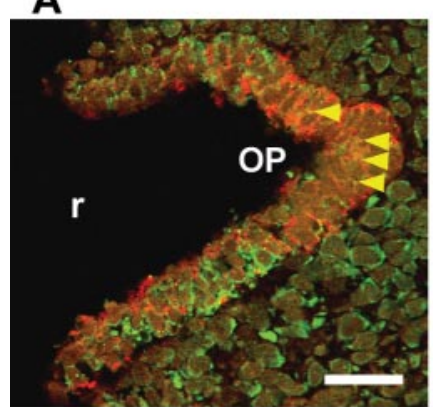

C

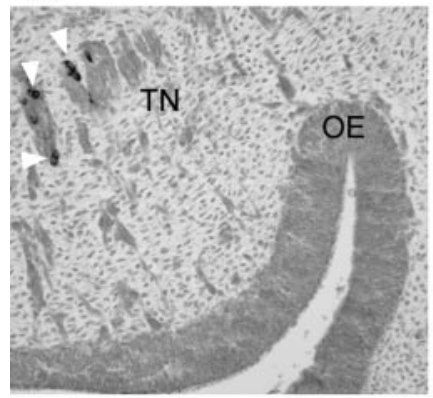

E

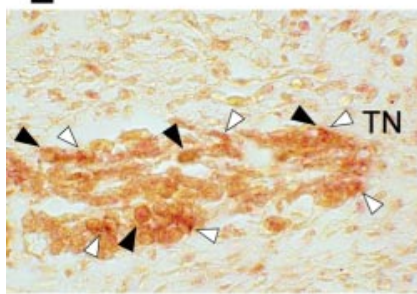

G
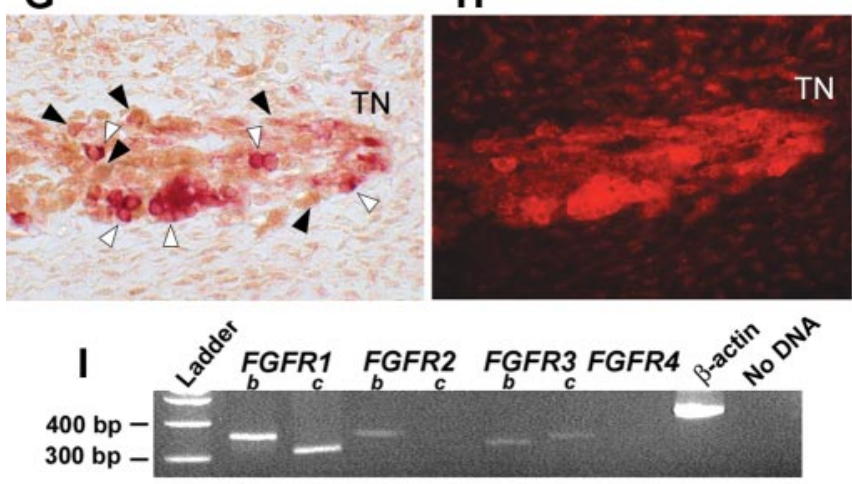

J
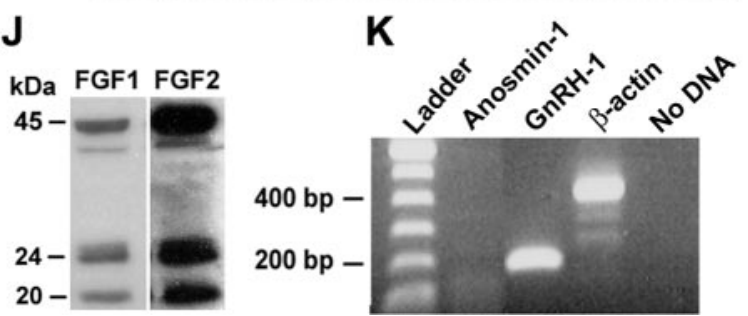

Figure 1. Expression of anosmin-1, FGFs, FGFRs, and GnRH. A, Immunohistofluorescence of a 4.5-week-old human embryo OP showing FGFR1 (FITC labeling) and GnRH (Texas Red labeling) protein distribution. Yellow arrowheads indicate sites of coexpression of these proteins in the medial region of the OP. B, The adjacent serial section, $7 \mu \mathrm{m}$ down from $A$, showing FGFR1 (FITC labeling) and anosmin-1 (Texas Red labeling) distribution in the OP. C, Section of a 7-week-old embryo showing the $\mathrm{OE}$ and TN area. The figure shows the presence of $\mathrm{GnRH}$ immunoreactive cells in clusters only within the TN (white arrowheads). D, The adjacent serial section of $C$, labeled with anti-anosmin- 1 antibody, shows the absence of anosmin- 1 in the $0 E$ at this stage. E, Double immunohistochemistry of an 8-week-old embryo section, showing anosmin-1 (brown DAB precipitates; black arrowheads) and FGFR1 (crimson Fast Red precipi-

C172R
\begin{tabular}{|l|l|l|l|l|l|l|l|}
\hline CR & WAP & Fnlll-1 & Fnlll-2 & Fnlll-3 & Fnlll-4 & H & V5 \\
\hline
\end{tabular}

PIWF4 or mPIWF4 $4^{172}$

\begin{tabular}{|c|c|c|c|}
\hline \multicolumn{4}{|c|}{$\underset{\text { 呙 }}{\mathrm{C} 172 \mathrm{R}}$} \\
\hline $\mathrm{CR}$ & WAP & Fnlll-1 & v5 \\
\hline
\end{tabular}

PIWF1 or mPIWF1 $1^{172}$

Figure 2. Schematic representation of the structure of recombinant anosmin-1 proteins produced in S2 cells. PIWF4 represents the wild-type anosmin-1, whereas PIWF1 is a truncated form with only one Fnlll domain. The WAP domain C172R point mutation (star) is present only in mPIWF4 and mPIWF1. CR, Cysteine-rich region; $\mathrm{H}$, histidine-rich region; V5, V5 epitope tag derived from Simian virus $5 ; 6$ His, $6 \times$ histidine tag.

FNC-B4 cell lysate, at least two major bands ( $\sim 188$ and $250 \mathrm{kDa})$ are also coprecipitated, indicating the presence of the FGFR1FGF2-HSPG complex. When recombinant anosmin-1 was added to the lysate, it was also brought down within this complex as detected by an anti-His antibody, consistent with a direct interaction of anosmin-1 with the FGFR1-FGF2-HSPG complex. The fact that although the amount of FGF2 within the complex is maintained, more HSPG seems to be integrated when anosmin-1 is present suggests a role of anosmin-1 in the formation of this complex (Fig. 4A). Anosmin-1 is a HS-binding protein, and it has been suggested that membrane-associated HSPGs might immobilize anosmin-1 to the cell surface (Soussi-Yanicostas et al., 1996). Immunocytochemistry of FNC-B4 cells incubated with anosmin-1 confirmed cell membrane adhesion of this protein, accompanied by concomitant induction of neurite outgrowth. The addition of exogenous HS caused dissociation of anosmin-1, likely because of competitive inhibition of binding to endogenous HS (Fig. $4 B$ ), resulting in loss of the neurite outgrowth phenotype. Taken together, these data support, although do not prove, the notion that there is an obligatory requirement of HS for the biological action of anosmin-1.

\section{Anosmin-1-induced MAPK activation is required for neurite outgrowth}

We next questioned whether the formation of an anosmin-1FGFR1-FGF2-HSPG complex activates a functional FGFR1 signaling pathway and assessed the activation of FGFR1 downstream effector MAPKs. FNC-B4 cells were growth arrested in serum-free medium for $24 \mathrm{hr}$ and stimulated with either $1 \mathrm{nM}$ anosmin-1 or 1.5 nM FGF2. Cells were then harvested at different time points and analyzed by Western blotting with phosphorylation-specific p42/44(ERK), p38, or JNK antibodies. Both anosmin-1 and FGF2 induced maximum phosphorylation of p42/44 and p38 within 30 min, which gradually decreased to basal level after $6 \mathrm{hr}$, whereas total p42/44 and p38 levels remained relatively constant (Fig. $4 C$ ). In contrast, no phosphory-

$\leftarrow$

tates; white arrowheads) in the TN. $F$, Flourescence image of $E$, confirming the expression of FGFR1 (red). G, Double immunohistochemistry on an adjacent serial section of $E$, showing anosmin-1 (brown DAB precipitates; black arrowheads) and GnRH (crimson Fast Red precipitates; white arrowheads) in the TN. $H$, Flourescence image of $G$, confirming the expression of GnRH (red). Scale bar: (in $A) A, B, 100 \mu \mathrm{m} ; C, D, 200 \mu \mathrm{m} ; E-H, 15 \mu \mathrm{m}$. r, Rostral. All sections are shown in sagittal orientation. I, $K$, Analysis of FNC-B4 cells using RT-PCR shows the presence of GnRH and different FGFR isoforms but no anosmin-1. $\beta$-Actin and no DNA were included as positive and negative controls. J, Expression of three different forms of FGF1 and FGF2 proteins are detected in FNC-B4 cells by Western blotting, suggesting the existence of a functional FGFR1 and GnRH pathway. Molecular weight markers are shown. 
lation of JNK was observed in these lysates, excluding the possible involvement of this pathway (data not shown). These results indicate that binding of anosmin-1 to FGFR1-FGF2-HSPG on the cell surface amplifies the FGFR1 signaling pathway response to endogenous FGF2, resulting in sustained phosphorylation of both $\mathrm{p} 42 / 44$ and p38 MAPKs. We next asked whether MAPK activation was required for anosmin-1-induced neurite outgrowth by conducting the assay in the presence of specific MAPK antagonists. The anosmin-1 effect was blocked by the addition of the MAPK kinase (MEK) inhibitor PD9859 (Pang et al., 1995) and the p38 inhibitor SB203580 (Iwasaki et al., 1999), indicating that these MAPKs mediate anosmin-1 effects (Fig. 3C,D).

\section{Anosmin-1 causes actin cytoskeleton reorganization via Cdc42-Rac1 pathway} Both neurite outgrowth and neuronal migration require the organized polymerization of F-actin to drive the forward cell membrane extension. We therefore determined whether anosmin-1 caused any changes in actin cytoskeletal organization. Immunofluorescence staining of F-actin and vinculin in FNC-B4 cells revealed that incubation with either FGF2 or anosmin-1, but not BSA, caused changes in the actin cytoskeleton within the cell soma and the growth cone, exhibiting filopodia and microspike formation with associated adhesion foci and complexes (Fig. 5A). BSA-treated cells showed a small number of stress fibers in the periphery of the cell, whereas after FGF2 and anosmin-1 treatments, a slightly greater number of stress fibers were observed. Scarce related focal adhesion complexes associated with actin arrays were also observed (Fig. 5A). Lamellipodium formation could not be detected in these cells, consistent with previous reports in human neuroepithelioma cells in which FGF2 failed to induce lamellipodium formation (van Weering et al., 1998). The Rho family of GTPases are one of the FGFR1 downstream effectors and the principal regulators of actin cytoskeletal rearrangements (Nikolic, 2002). We asked whether the anosmin-1-induced activation of the FGFR1 signal pathway also led to activation of the Rho family, particularly Cdc42 and Rac1. Because only the GTP-bound activated form of Cdc42 and Rac1 bind to their common downstream effector PAK1, we used the highly conserved p21binding domain (PBD) of PAK1 (Daniels et al., 1998; Iwasaki et al., 1999) conjugated to agarose beads to pull down the
A
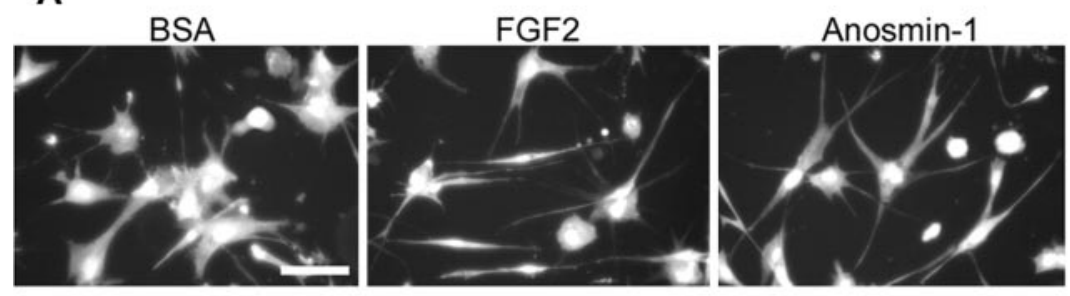

B

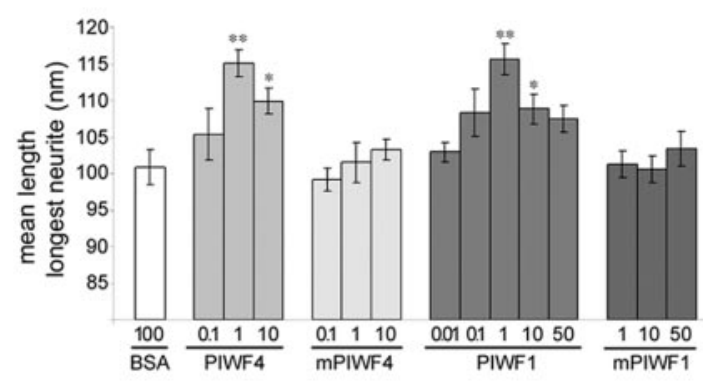

C

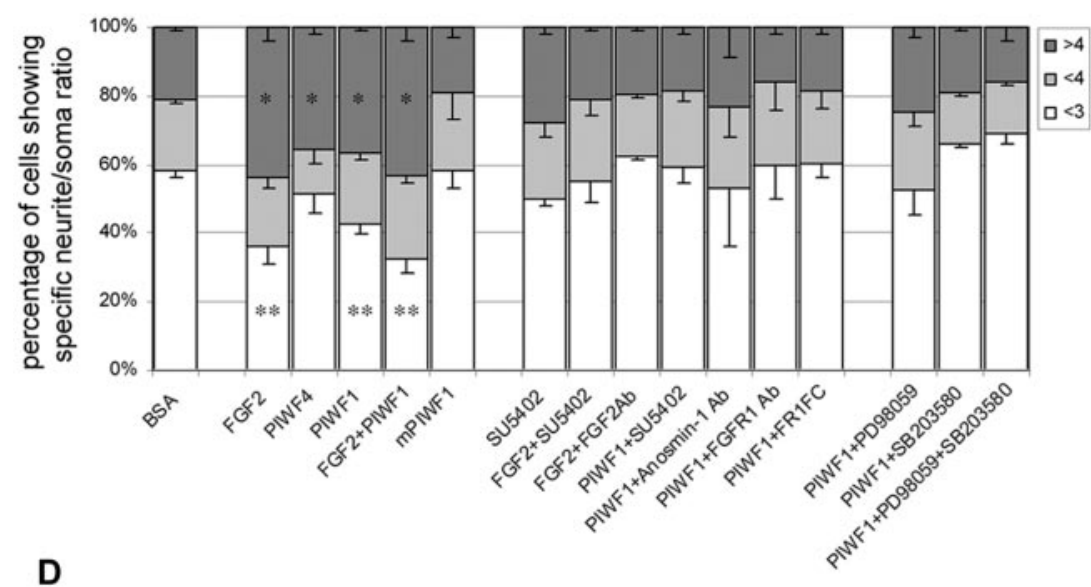

\begin{tabular}{|l|c|c|c|c|}
\hline \multicolumn{1}{|c|}{ Treatment } & Ratio $<3$ & Ratio $<4$ & Ratio $>4$ & $\begin{array}{c}\text { Total number of } \\
\text { cells analysed }\end{array}$ \\
\hline BSA & $58 \pm 2(223)$ & $21 \pm 1(81)$ & $21 \pm 1(81)$ & 384 \\
\hline FGF2 & $36 \pm 5(159)$ & $20 \pm 3(86)$ & $45 \pm 4(196)$ & 431 \\
\hline PIWF4 & $52 \pm 6(138)$ & $12 \pm 4(33)$ & $36 \pm 2(96)$ & 267 \\
\hline PIWF1 & $43 \pm 3(224)$ & $21 \pm 2(110)$ & $37 \pm 1(194)$ & 523 \\
\hline FGF2 + PIWF1 & $32 \pm 4(69)$ & $24 \pm 2(52)$ & $43 \pm 4(94)$ & 215 \\
\hline mPIWF1 & $58 \pm 5(124)$ & $23 \pm 8(49)$ & $19 \pm 3(41)$ & 214 \\
\hline SU5402 & $50 \pm 2(104)$ & $22 \pm 4(46)$ & $28 \pm 2(58)$ & 208 \\
\hline FGF2 + SU5402 & $41 \pm 6(80)$ & $35 \pm 5(68)$ & $25 \pm 1(47)$ & 195 \\
\hline FGF2 + FGF2Ab & $63 \pm 1(166)$ & $17 \pm 1(45)$ & $20 \pm 1(53)$ & 264 \\
\hline PIWF1 + SU5402 & $60 \pm 5(175)$ & $22 \pm 3(64)$ & $19 \pm 2(53)$ & 292 \\
\hline PIWF1 + An0Smin-1 Ab & $53 \pm 17(159)$ & $24 \pm 9(72)$ & $23 \pm 9(69)$ & 300 \\
\hline PIWF1 + FGFR1 Ab & $60 \pm 10(138)$ & $24 \pm 8(55)$ & $16 \pm 2(38)$ & 231 \\
\hline PIWF1 + FR1FC & $61 \pm 4(112)$ & $21 \pm 5(38)$ & $19 \pm 2(33)$ & 183 \\
\hline PIWF1 + PD98059 & $53 \pm 7(110)$ & $23 \pm 4(47)$ & $25 \pm 3(50)$ & 207 \\
\hline PIWF1 + SB203580 & $66 \pm 1(133)$ & $15 \pm 1(30)$ & $19 \pm 1(38)$ & 202 \\
\hline PIWF1 + PD98059 + SB203580 & $69 \pm 3(154)$ & $15 \pm 1(34)$ & $16 \pm 4(36)$ & 224 \\
\hline
\end{tabular}

Figure 3. Anosmin-1 induces neurite outgrowth via FGFR1 and MAPK signaling pathways. $A$, Morphology of FNC-B4 cells in three-dimensional collagen culture treated with BSA, FGF2, or anosmin-1 proteins. Scale bar, $5 \mu \mathrm{m}$. B, Dose-dependent effects of wild-type or mutant anosmin-1 recombinant proteins on the mean length of the longest neurites. Values are the mean \pm SE. $p<$ 0.01 compared with the BSA control $\left(^{*}\right)$ or between different protein concentration $\left(^{* *}\right)$ are indicated; $n=1000$ for each independent experiment. $C, D$, The neurite/soma ratio of cells after indicated treatments. $C$, The percentage of cells exhibiting a neurite/soma ratio $<3(<3)$, between 3 and $4(<4)$, or higher than $4(>4)$ after each treatment are shown in the graph. Average values \pm SE from five independent experiments are shown. Statistical comparison has been computed between the $>4$ group of different treatment and that of BSA control ( ${ }^{*} p<0.01$ ) and between the $<3$ group of different treatment and that of BSA control $\left({ }^{* *} p<0.01\right)$. There was no significant difference among $<4$ groups. $D$, The average percentage \pm SE along with the actual numbers of cells (in parentheses) exhibiting the indicated neurite/soma ratio are also shown as a table. 

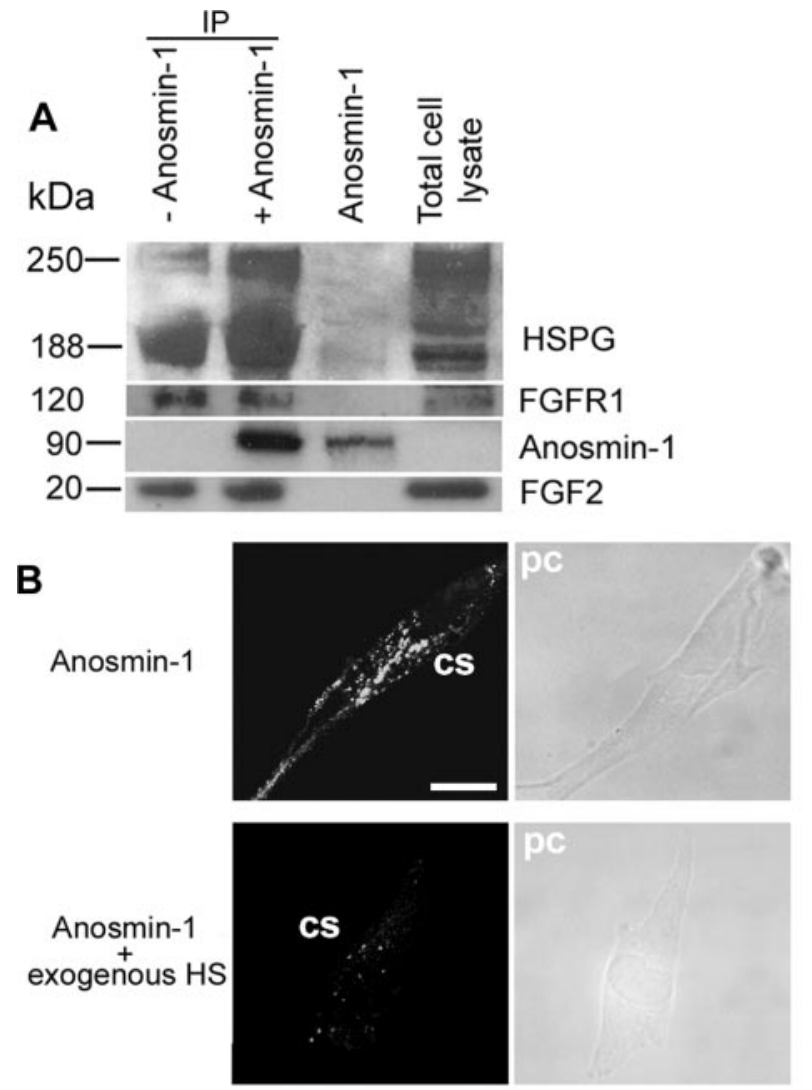

C

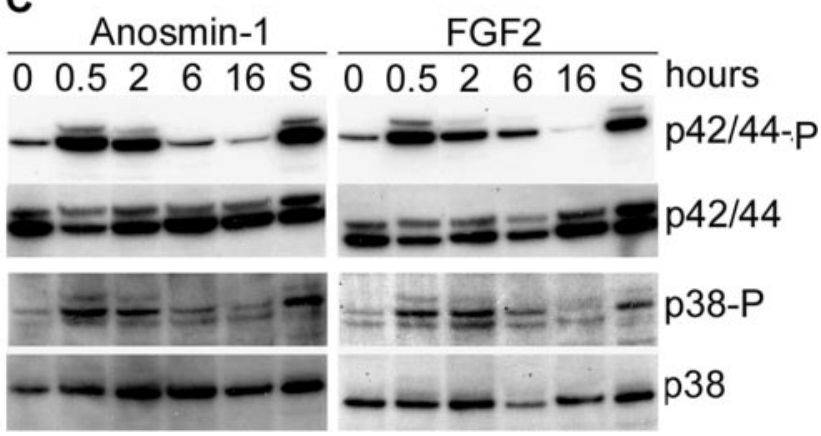

Figure 4. Association of anosmin-1 with FGFR1/FGF2/HSPG on the cell surface induces MAPK phosphorylation. A, Western blot analysis of FGFR1 immunoprecipitation (IP) using FNC-B4 cell lysates with ( + Anosmin) or without ( - Anosmin) the addition of exogenous anosmin-1. Recombinant anosmin-1 alone or total cell lysate was included as a control. From the different species of the endogenous HSPGs present in the total cell lysate, the two major bands recruited in the complex are marked with arrows. Protein molecular weight markers are indicated. $B$, Immunofluorescence images demonstrating that cell-surface association of anosmin-1 is mediated by HS. Panels show cell surface (cs)-associated protein and corresponding phase-contrast (pc) image of the same cell with or without the addition of HS. Scale bar, 5 $\mu \mathrm{m}$. C, Phosphorylation status of p $42 / 44$ and p 38 MAPK were analyzed by Western blotting at the indicated time points after the addition of anosmin-1 or FGF2 in serum-starved cultures. The levels of total p42/44 and $\mathrm{p} 38$ proteins are also shown. Cells grown in serum containing F-12 medium (S) were included as a positive control.

GTP-bound Cdc42 and Rac1 proteins. When Western blotting was performed on the eluted protein complexes and the band intensity was analyzed by densitometry, cells stimulated with either FGF2 or anosmin-1 showed a higher level of Cdc42-GTP and Rac1-GTP, compared with that of BSA treatment, indicating these pathways are also induced by anosmin-1 signaling and support the actin reorganization in these cells (Fig. 5B).

In summary, these results provide compelling evidence that
A
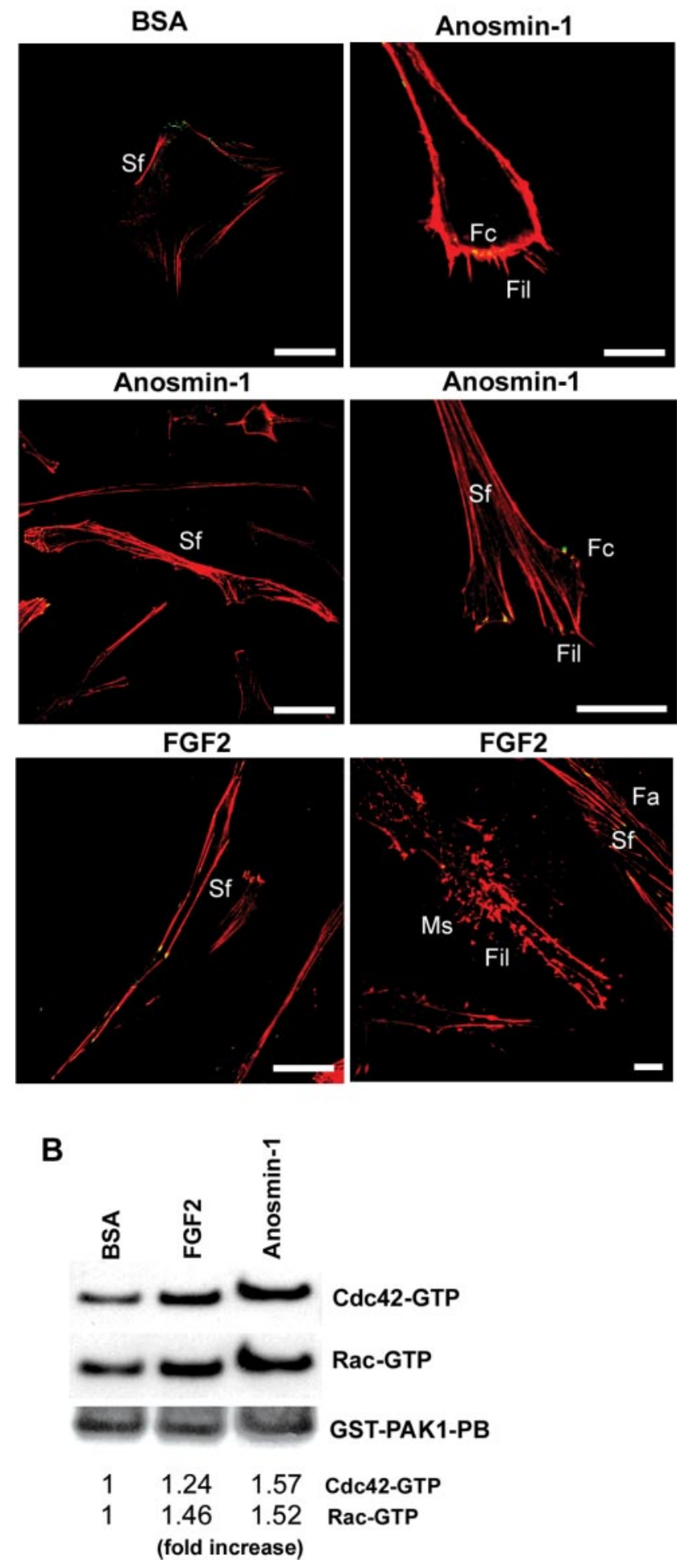

Figure 5. Anosmin-1 causes cytoskeleton reorganization through Cdc42-Rac1 pathway. $A$, Vinculin (FITC labeling; green arrows) and phalloidin (Texas Red labeling) staining reveals organization of actin cytoskeleton in FNC-B4 cells after BSA, FGF2, or anosmin-1 treatments. Left, Individual cells exhibiting F-actin stress fibers (Sf) after different treatments. Right, F-actin reorganization forming filopodia (Fil) and microspikes (Ms) in the growth cones, accompanied by adhesion complexes ( $\mathrm{Fc}$ ) and focal adhesion (Fa). Scale bars: left, $10 \mu \mathrm{m}$; right, $5 \mathrm{~nm}$. B, The activated (GTP-bound) Cdc42 or Rac1 proteins are pulled down by GST-PAK1-PBD-conjugated agarose beads and analyzed by Western blotting. The level of GST-PAK1-PBD is shown as loading control. Intensity of the bands under different treatments is quantified by densitometry, and the fold of increase with respect to BSA is indicated. The values are normalized to the GST-PAK1-PBD levels. 
anosmin-1 enhances neuronal differentiation-related phenotypic changes in FNC-B4 cells by activating FGFR1 and its downstream signaling pathways. Nonetheless, the exact requirements for anosmin- 1 activity in enhancing the FGFR1/FGF2 signaling were still unclear. Alternative splicing of the extracellular Ig-like domains generates different FGFR isoforms with specific ligand-binding properties in a tissue-specific manner (Groth and Lardelli, 2002). FNC-B4 cells express a range of other FGFR isoforms and ligands; other cell type-specific factors present in FNC-B4 cells might also influence the action of anosmin-1. To clarify these issues, we used a heterologous BaF3 lymphoid cell system in which the activity of anosmin-1 on specific FGFR isoforms can be directly tested in the presence or absence of HS.

\section{Anosmin-1 enhances FGF2/FGFR1 signaling in BaF3 cells}

$\mathrm{BaF} 3$ is a mouse B-cell lineage dependent on IL-3 for its growth and survival (Palacios and Steinmetz, 1985). They do not express endogenous FGFRs or HSPGs and do not proliferate in response to FGF2 or heparin alone (data not shown). BaF3 derivatives transfected with single isoforms of the each FGFR have been engineered. In the absence of IL-3, these cells rely on FGFR activation by exogenous FGF and HS; thus, specificity of various ligand-receptor interactions can be assessed by measuring their relative mitogenic activity (Ornitz et al., 1996). We first examined the effects of anosmin-1 in FGFR1 IIIc-transfected BaF3cells by a colorimetric MTT assay. Increasing amounts of anosmin-1, either alone or in combination with a suboptimal concentration of FGF2 (300 pM) or heparin $(300 \mathrm{ng} / \mathrm{ml})$ individually did not show any effects on proliferation, indicating that anosmin-1 cannot directly substitute for any of the molecules normally involved in FGF signaling. Anosmin-1 did not enhance the mitogenic activity of IL-3 (Fig. 6A). In the presence of both FGF2 and heparin, however, the addition of anosmin-1 caused a significant and marked dose-dependent increase in cell proliferation (Fig. 6A). Therefore, in the presence of anosmin-1, FGFR1 IIIc-mediated mitogenic responses to particular concentrations of FGF2 are amplified. HS was sufficient to mediate this effect, excluding the possible requirement for other neuronal cell type-specific elements. Enhancement of proliferative responses were even observed with higher concentrations of FGF2 (1 nM) and heparin $(10 \mu \mathrm{g} / \mathrm{ml})$ that would normally generate a maximal FGFRmediated response in these cells (Fig. 6B). These supramaximal responses clearly support the notion that anosmin-1 acts to amplify signaling responses to particular concentrations of FGF2. Furthermore, our findings in FNC-B4 cells in which anosmin-1 alone was effective without the addition of exogenous FGF2 (Figs. $3,4 C, 5$ ) are also consistent with a mechanism that involves augmentation of responses to endogenous levels of FGF2.

Because FGF2 is a potent activator of mostly the $\mathrm{c}$ isoforms of all FGFRs (Ornitz et al., 1996) and FNC-B4 cells express multiple isoforms of FGFR1, FGFR2, and FGFR3, we investigated whether anosmin-1 could differentially modulate FGFR isoforms. Anosmin-1 was unable to induce proliferation of cells expressing FGFR2 IIIc or FGFR3 IIIc under similar conditions (Fig. 6B). Therefore, at least for the $c$ isoforms, anosmin-1 is a FGFR1specific modulatory co-ligand that enhances FGF2 signaling. However, the truncated anosmin-1, PIWF1, failed to induce a significant increase in cell proliferation, suggesting that all four FnIII domains of anosmin-1 are required to activate FGF2/ FGFR1 IIIc signaling in this cell system (Fig. 6C).

\section{Discussion}

During early neuronal development, olfactory axons and GnRH neurons travel through diverse embryonic compartments and undergo different morphological and physiological changes. A body of evidence suggests that ECM proteins, cell adhesion molecules, growth factors, and chemotactic factors participate in regulating neural cell behavior and morphology, thus determining how cells respond to their environment. It has been suggested that anosmin-1 is an adhesion molecule for different neuronal and non-neuronal cell types and may modulate neurite outgrowth in a cell type-specific manner (Soussi-Yanicostas et al., 1998). The identity of the cell surface receptor(s) for anosmin-1, however, has been unknown, and it was speculated that HS might be a cofactor stabilizing anosmin-1 binding. Our study shows that anosmin-1 acts as an FGFR1-specific modulatory co-ligand that physically interacts with the FGFR1-FGF2-HSPG complex and amplifies the resulting downstream signaling responses. In human embryonic olfactory GnRH neuroblasts, anosmin-1mediated activation of the FGFR1 pathway induced neurite outgrowth and cytoskeletal reorganization. This occurred via sustained MAPK phosphorylation and Cdc42/Racl activation, at levels equivalent to or higher than those induced by the addition of high concentrations of exogenous FGF2. In the presence of anosmin-1, therefore, the level of cellular responses to particular concentrations of FGF2 is increased. Our results using BaF3 cells indicate that anosmin-1 effect is specific to the FGFR1 IIIc isoform, although additional work is clearly warranted to evaluate a potential role for anosmin-1 in regulating the IIIb isoforms.

Our investigation on the spatiotemporal distribution of GnRH/anosmin-1/FGFR1 during early human brain development further support these in vitro observations and suggest their possible functional interaction in vivo. We have demonstrated the presence of anosmin-1 and FGFR1 in the OP region where the pioneer GnRH neurons lie. Later on at 7 weeks, when the OP has developed into $\mathrm{OE}$ and the GnRH neurons have migrated, neither anosmin-1 nor FGFR1 expression could be found in the OE. One week later, the presence of anosmin-1 along with FGFR1and GnRH-expressing cells within the TN region was evident. This is the first time an 8-week-old embryo has been studied for these proteins. Previous studies in human have shown anosmin-1 expression in the OB presumptive region from week 5 onward. It has been also detected in the medial walls of the primitive cerebral 
hemispheres within the later migratory routes of $\mathrm{GnRH}$-releasing neurons (Hardelin et al., 1999). In the musk shrew, anosmin-1 is demonstrable in the $\mathrm{OB}$, but it is also detected in the $\mathrm{OE}$, the frontonasal region along the extracerebral course of the olfactory, vomeronasal, and TN fibers, all of which are associated with migrating GnRH neurons (Dellovade et al., 2003). Furthermore, recent studies in mouse by Gill et al. (2004) support the contention that FGFR1 signaling is involved in early GnRH neuronal fate as well as migration. Combined with our current data, these observations suggest a permissive or instructive role of FGFR1/ FGF2/anosmin-1-mediated signaling during olfactory GnRH neuronal establishment. Thus, disruption of anosmin-1/FGFR1 signaling events would be expected to contribute to the pathogenesis of KS. In the X-linked form of this disorder, early GnRH and olfactory neuronal development appears intact, suggesting that the disease phenotype represents a disturbance of later bulb/ GnRH neuronal ontogeny. Therefore, it is possible that anosmin1/FGFR1 signaling events demonstrated here are similarly involved in bulb histogenesis proper and/or the establishment of neuronal connectivity between incoming olfactory sensory neurons and mitral cells within the bulb. Anosmin-1-mediated FGFR1 signaling may also be involved in mitral cell proliferation and survival, as well as outgrowth of collaterals from the mitral and tufted cell axons to the olfactory cortex, as demonstrated previously (Soussi-Yanicostas et al., 2002).

To our knowledge, anosmin-1 is the first human protein identified as a positive regulator of FGFR1 signaling through an isoform-specific mechanism, the loss of which is associated with a clinical disorder. There are, thus far, few factors known to increase FGFR1 activity by extracellularly interacting with its ectodomain (Tsang and Dawid, 2004). Sef (Tsang et al., 2002) and XFLRT3 (Bottcher et al., 2004) are transmembrane proteins containing extracellular FnIII domains. Sef, first identified in zebrafish, inhibits FGFR signaling by preventing FRS2 phosphorylation, and Sef-b, the cytoplasmic isoform, blocks MEK activity. On the other hand, XFLRT3 promotes FGF8 signaling through a FnIII domain-mediated interaction with FGFR1 in Xenopus by as yet unknown mechanisms. Although there is no evidence that any of these factors is related to anosmin-1, it is plausible that there are multiple regulators of the FGF signaling pathway expressed in specific spatiotemporal patterns in different cell types using different modes of action. These molecules may represent an additional level of complexity in the network of molecules involved in regulation of FGFR signal transduction during development.

It has been suggested that cells are capable of sensing the differences in duration and intensity of extracellular signals triggering different effector pathways accordingly and that p42/44 MAPK phosphorylation may be the cellular interpretation machinery (Marshall, 1995; Harada et al., 2001). Our data in FNC-B4 cells show that anosmin-1- and FGF2-mediated FGFR1 signaling results in sustained MAPK phosphorylation that is maintained over a few hours. The MAPK pathway has been implicated in neurite outgrowth in different neuronal cell lines (Pang et al., 1995; Iwasaki et al., 1999); in PC12 cells, sustained, but not transient, phosphorylation of p42/44 can induce growth arrest and differentiation. Studies have shown that only this type of MAPK activation results in p35 induction, a neuron-specific activator of cyclin-dependent kinase (cdk) 5 (Harada et al., 2001). The Rho family of small GTPases regulates actin-based cellular motility during neuronal differentiation. Typically, Cdc42 and Racl induce, whereas RhoA inhibits, neurite outgrowth. The neuron-specific expression and cell membrane association of PAK1, a downstream effector of both Rac1 and Cdc42, induces cytoskeletal changes, and its role during neurite outgrowth and axonal pathfinding is established (Nikolic, 2002). One of the effector kinases regulated by Rac1 is p35. cdk5/p35 kinase activity, which modulates PAK1 function (Nikolic et al., 1998), is induced only in differentiating neuronal cells (Nikolic, 2002). In anosmin-1-treated FNC-B4 cells, we demonstrated that Rac1 and Cdc42 were activated and bound to PAK1, suggesting these effector pathways may be responsible for the anosmin-1-induced reorganization of F-actin and neurite outgrowth.

Several speculations can be made regarding the possible mechanism of action of anosmin-1 within the FGFR1-FGF2HSPG signaling complex. Anosmin-1 may facilitate receptor dimerization and stabilize the assembly in conjunction with HSPG, increasing the duration or intensity of the signal. Alternatively, anosmin-1 may anchor onto FGFR1 to attract FGF2 and HS for rapid receptor recognition. Our data do not preclude a direct interaction of anosmin-1 with FGFR1, although the dissociation of anosmin-1 from cells in the presence of exogenous HS (Fig. $4 B$ ) is consistent with either a weak anosmin-1-FGFR1 interaction or an interaction that is strongly HS dependent. It is also possible that anosmin-1 determines the specificity of HS being recruited during certain developmental stages. In BaF3 cells, only full-length anosmin-1 with four FnIII domains (PIWF4), but not truncated PIWF1, was functional, unlike in FNC-B4. This may be because of the differences between the endogenous HSPGs present in FNC-B4 cells and the exogenous heparin used in BaF3 assays. The exact HS structural requirement and its effect on the activity of anosmin-1 on FGFs and FGFRs other than those tested here are currently under investigation. Our observation that a C172R mutation in the evolutionarily conserved WAP domain blocks its function (Fig. $3 B-D$ ), together with previous reports describing X-KS-related mutations that disrupt the disulfide core motif (Oliveira et al., 2001; Sato et al., 2004), support the functional and structural importance of this region. Our current investigation of the structural relationship among these molecules should resolve such questions.

Our study is the first report describing a defined molecular mechanism of anosmin-1 function and provides novel insights into how FGFR1 signaling is regulated and fine-tuned during the olfactory GnRH system development. The present work also identifies a potential mechanism underlying the link between $\mathrm{A}-\mathrm{KS}$ and X-KS. Furthermore, our data showing the dosedependent effect of anosmin-1 on the FGFR1 signal responses provide a molecular basis for understanding the greater prevalence of KS in males. In females, the KAL-1 gene partially escapes X-inactivation (Franco et al., 1991), leading to a higher level of anosmin-1 expression when compared with males; this may compensate for partial loss (haploinsufficiency) of FGFR1 signaling in heterozygous females.

\section{References}

Anderson J, Burns HD, Enriquez-Harris P, Wilkie AO, Heath JK (1998) Apert syndrome mutations in fibroblast growth factor receptor 2 exhibit increased affinity for FGF ligand. Hum Mol Genet 7:1475-1483.

Bottcher RT, Pollet N, Delius H, Niehrs C (2004) The transmembrane protein XFLRT3 forms a complex with FGF receptors and promotes FGF signalling. Nat Cell Biol 6:38-44.

Britto JA, Evans RD, Hayward RD, Jones BM (2002) Toward pathogenesis of Apert cleft palate: FGF, FGFR, and TGF beta genes are differentially expressed in sequential stages of human palatal shelf fusion. Cleft Palate Craniofac J 39:332-340.

Bulow HE, Hobert O (2004) Differential sulfations and epimerization define heparan sulfate specificity in nervous system development. Neuron 41:723-736.

Bulow HE, Berry KL, Topper LH, Peles E, Hobert O (2002) Heparan sulfate 
proteoglycan-dependent induction of axon branching and axon misrouting by the Kallmann syndrome gene kal-1. Proc Natl Acad Sci USA 99:6346-6351.

Coumoul X, Deng CX (2003) Roles of FGF receptors in mammalian development and congenital diseases. Birth Defects Res Part C Embryo Today 69:286-304.

Daniels RH, Hall PS, Bokoch GM (1998) Membrane targeting of p21activated kinase 1 (PAK1) induces neurite outgrowth from PC12 cells. EMBO J 17:754-764.

Dellovade TL, Hardelin JP, Soussi-Yanicostas N, Pfaff DW, SchwanzelFukuda M, Petit C (2003) Anosmin-1 immunoreactivity during embryogenesis in a primitive eutherian mammal. Brain Res Dev Brain Res 140:157-167.

Dode C, Levilliers J, Dupont JM, De Paepe A, Le Du N, Soussi-Yanicostas N, Coimbra RS, Delmaghani S, Compain-Nouaille S, Baverel F, Pecheux C, Le Tessier D, Cruaud C, Delpech M, Speleman F, Vermeulen S, Amalfitano A, Bachelot Y, Bouchard P, Cabrol S, et al. (2003) Loss-offunction mutations in FGFR1 cause autosomal dominant Kallmann syndrome. Nat Genet 33:463-465.

Dono R (2003) Fibroblast growth factors as regulators of central nervous system development and function. Am J Physiol Regul Integr Comp Physiol 284:R867-R881.

Ensoli F, Fiorelli V, Vannelli B, Barni T, De Cristofaro M, Ensoli B, Thiele CJ (1998) Basic fibroblast growth factor supports human olfactory neurogenesis by autocrine/paracrine mechanisms. Neuroscience 86:881-893.

Franco B, Guioli S, Pragliola A, Incerti B, Bardoni B, Tonlorenzi R, Carrozzo R, Maestrini E, Pieretti M, Taillon-Miller P (1991) A gene deleted in Kallmann's syndrome shares homology with neural cell adhesion and axonal path-finding molecules. Nature 353:529-536.

Gill JC, Moenter SM, Tsai PS (2004) Developmental regulation of gonadotropin-releasing hormone neurons by fibroblast growth factor signaling. Endocrinology 145:3830-3839.

Graziadei PP, Monti Graziadei GA (1986) Principles of organization of the vertebrate olfactory glomerulus: an hypothesis. Neuroscience 19:1025-1035.

Groth C, Lardelli M (2002) The structure and function of vertebrate fibroblast growth factor receptor 1. Int J Dev Biol 46:393-400.

Guimond SE, Turnbull JE (1999) Fibroblast growth factor receptor signalling is dictated by specific heparan sulphate saccharides. Curr Biol 9:1343-1346.

Harada T, Morooka T, Ogawa S, Nishida E (2001) ERK induces p35, a neuron-specific activator of Cdk5, through induction of Egr1. Nat Cell Biol 3:453-459.

Hardelin JP, Julliard AK, Moniot B, Soussi-Yanicostas N, Verney C, SchwanzelFukuda M, Ayer-Le Lievre C, Petit C (1999) Anosmin-1 is a regionally restricted component of basement membranes and interstitial matrices during organogenesis: implications for the developmental anomalies of $\mathrm{X}$ chromosome-linked Kallmann syndrome. Dev Dyn 215:26-44.

Hebert JM, Lin M, Partanen J, Rossant J, McConnell SK (2003) FGF signaling through FGFR1 is required for olfactory bulb morphogenesis. Development 130:1101-1111.

Hu Y, Gonzalez-Martinez D, Kim SH, Bouloux P (2004) Cross talk of anosmin-1, the protein implicated in X-linked Kallmann's syndrome, with heparan sulphate and urokinase-type plasminogen activator. Biochem $\mathrm{J}$, in press.

Iwasaki S, Iguchi M, Watanabe K, Hoshino R, Tsujimoto M, Kohno M (1999) Specific activation of the p38 mitogen-activated protein kinase signaling pathway and induction of neurite outgrowth in PC12 cells by bone morphogenetic protein-2. J Biol Chem 274:26503-26510.

Legouis R, Hardelin JP, Levilliers J, Claverie JM, Compain S, Wunderle V, Millasseau P, Le Paslier D, Cohen D, Caterina D, (1991) The candidate gene for the X-linked Kallmann syndrome encodes a protein related to adhesion molecules. Cell 67:423-435.

MacColl G, Bouloux P, Quinton R (2002) Kallmann syndrome: adhesion, afferents, and anosmia. Neuron 34:675-678.

Marshall CJ (1995) Specificity of receptor tyrosine kinase signaling: transient versus sustained extracellular signal-regulated kinase activation. Cell 80:179-185.

Meyers EN, Lewandoski M, Martin GR (1998) An Fgf8 mutant allelic series generated by Cre- and Flp-mediated recombination. Nat Genet 18:136-141.

Mohammadi M, McMahon G, Sun L, Tang C, Hirth P, Yeh BK, Hubbard SR, Schlessinger J (1997) Structures of the tyrosine kinase domain of fibro- blast growth factor receptor in complex with inhibitors. Science 276:955-960.

Nikolic M (2002) The role of Rho GTPases and associated kinases in regulating neurite outgrowth. Int J Biochem Cell Biol 34:731-745.

Nikolic M, Chou MM, Lu W, Mayer BJ, Tsai LH (1998) The p35/Cdk5 kinase is a neuron-specific Rac effector that inhibits Pak1 activity. Nature 395:194-198.

Oliveira LM, Seminara SB, Beranova M, Hayes FJ, Valkenburgh SB, Schipani E, Costa EM, Latronico AC, Crowley Jr WF, Vallejo M (2001) The importance of autosomal genes in Kallmann syndrome: genotypephenotype correlations and neuroendocrine characteristics. J Clin Endocrinol Metab 86:1532-1538.

Ornitz DM, Xu J, Colvin JS, McEwen DG, MacArthur CA, Coulier F, Gao G, Goldfarb M (1996) Receptor specificity of the fibroblast growth factor family. J Biol Chem 271:15292-15297.

Palacios R, Steinmetz M (1985) IL-3-dependent mouse clones that express B-220 surface antigen, contain Ig genes in germ-line configuration, and generate B lymphocytes in vivo. Cell 41:727-734.

Pang L, Sawada T, Decker SJ, Saltiel AR (1995) Inhibition of MAP kinase kinase blocks the differentiation of PC-12 cells induced by nerve growth factor. J Biol Chem 270:13585-13588.

Robertson A, MacColl GS, Nash JA, Boehm MK, Perkins SJ, Bouloux PM (2001) Molecular modelling and experimental studies of mutation and cell-adhesion sites in the fibronectin type III and whey acidic protein domains of human anosmin-1. Biochem J 357:647-659.

Romanelli RG, Barni T, Maggi M, Luconi M, Failli P, Pezzatini A, Pelo E, Torricelli F, Crescioli C, Ferruzzi P, Salerno R, Marini M, Rotella CM, Vannelli GB (2004) Expression and function of gonadotropin-releasing hormone $(\mathrm{GnRH})$ receptor in human olfactory $\mathrm{GnRH}$-secreting neurons: an autocrine GnRH loop underlies neuronal migration. J Biol Chem 279:117-126.

Sato N, Katsumata N, Kagami M, Hasegawa T, Hori N, Kawakita S, Minowada S, Shimotsuka A, Shishiba Y, Yokozawa M, Yasuda T, Nagasaki K, Hasegawa D, Hasegawa Y, Tachibana K, Naiki Y, Horikawa R, Tanaka T, Ogata T (2004) Clinical assessment and mutation analysis of Kallmann syndrome 1 (KAL1) and fibroblast growth factor receptor 1 (FGFR1, or KAL2) in five families and 18 sporadic patients. J Clin Endocrinol Metab 89:1079-1088.

Schwanzel-Fukuda M, Pfaff DW (1989) Origin of luteinizing hormonereleasing hormone neurons. Nature 338:161-164.

Simon MA (2000) Receptor tyrosine kinases: specific outcomes from general signals. Cell 103:13-15.

Soussi-Yanicostas N, Hardelin JP, Arroyo-Jimenez MM, Ardouin O, Legouis R, Levilliers J, Traincard F, Betton JM, Cabanie L, Petit C (1996) Initial characterization of anosmin-1, a putative extracellular matrix protein synthesized by definite neuronal cell populations in the central nervous system. J Cell Sci 109:1749-1757.

Soussi-Yanicostas N, Faivre-Sarrailh C, Hardelin JP, Levilliers J, Rougon G, Petit C (1998) Anosmin-1 underlying the X chromosome-linked Kallmann syndrome is an adhesion molecule that can modulate neurite growth in a cell-type specific manner. J Cell Sci 111:2953-2965.

Soussi-Yanicostas N, de Castro F, Julliard AK, Perfettini I, Chedotal A, Petit C (2002) Anosmin-1, defective in the X-linked form of Kallmann syndrome, promotes axonal branch formation from olfactory bulb output neurons. Cell 109:217-228.

Tobet SA, Bless EP, Schwarting GA (2001) Developmental aspect of the gonadotropin-releasing hormone system. Mol Cell Endocrinol 185:173-184.

Tsang M, Dawid IB (2004) Promotion and attenuation of FGF signaling through the Ras-MAPK pathway. Sci STKE 2004:e17.

Tsang M, Friesel R, Kudoh T, Dawid IB (2002) Identification of Sef, a novel modulator of FGF signalling. Nat Cell Biol 4:165-169.

Vannelli GB, Ensoli F, Zonefrati R, Kubota Y, Arcangeli A, Becchetti A, Camici G, Barni T, Thiele CJ, Balboni GC (1995) Neuroblast long-term cell cultures from human fetal olfactory epithelium respond to odors. J Neurosci 15:4382-4394.

van Weering DH, de Rooij J, Marte B, Downward J, Bos JL, Burgering BM (1998) Protein kinase B activation and lamellipodium formation are independent phosphoinositide 3-kinase-mediated events differentially regulated by endogenous Ras. Mol Cell Biol 18:1802-1811.

Wray S, Grant P, Gainer H (1989) Evidence that cells expressing luteinizing hormone-releasing hormone mRNA in the mouse are derived from progenitor cells in the olfactory placode. Proc Natl Acad Sci USA 86:81328136. 